\title{
Pedagogical Technologies for the Development of the Speech Competence of Future Specialists in Non-Linguistic Universities
}

\author{
Sayyora Saidjajalova ${ }^{1}$ \\ ${ }^{1}$ Tashkent Branch of Moscow State University named after M. V. Lomonosov, Amir Timur, 22, 100000, Tashkent, Uzbekistan
}

\begin{abstract}
The main task of modern society, the change in educational policy in general and in the field of teaching speech disciplines are discussed in this article. An analysis of pedagogical practice and the results of special studies suggest that the problem of using these technologies to develop the speech competence of future specialists of non-linguistic universities in the process of teaching the Russian language has not yet been adequately reflected in the research of scientists. It is also said that many problems in higher education, in particular, the use of pedagogical technologies in teaching the Russian language, are poorly solved in both theoretical and practical aspects.
\end{abstract}

\section{Introduction}

Language is the most important means of communication, without which the existence and development of human society is impossible. The changes taking place today in social relations, means of communication require an increase in the communicative competence of students, improvement of their speech training so that they can exchange thoughts in various situations in the process of interacting with other communication participants, while correctly using the system of language and speech norms.

The challenges facing by higher education today require the improvement of the educational process aimed at increasing the creative potential of students' educational activities. The basis for ensuring high quality education is the use of effective educational technologies, the integration of the educational process and scientific activities and the involvement of students in it, the individualization of teaching and upbringing, the creation in a higher educational institution of a trusting atmosphere of creative cooperation, continuous self-development and self-realization of students in the educational process.

One of the main tasks of modern society is to change educational policy in general and in the field of teaching speech disciplines as well. The top priority in education today is not so much the acquisition of a large amount of knowledge by students as the development of their intellectual and creative potential, which allows them to produce new knowledge in the future. In this regard, the principles of traditional education are being reformed, largely due to the social order.

Teaching speech skills is implemented within the framework of a student-centered approach, which involves the individualization of training, taking into account the level of language proficiency, the level of intellectual development and individual psychological characteristics of students. It means that the center of learning is the student's personality, his motives, goals, and a special psychological makeup, which together determines the nature of learning. This approach forms the student's activity, his readiness for learning activities, for solving problem problems through partnership with the teacher.

In modern learning conditions, such qualities of students should be developed as: the ability to independently acquire knowledge and apply it in practice; the ability to think critically and creatively, to produce new ideas;

the ability to work with information, analyze it and highlight the main thing; the ability to work in a team, coordinate with others and avoid conflict situations.

Pedagogical technologies, which have recently been widely used in modern education, are aimed at the formation and development of the above qualities of students.

\section{Methods}

Pedagogical technology is the design of the educational process, based on the use of a set of methods, techniques and forms of organizing training and educational activities that increase the effectiveness of training, the use of which has a clearly defined result. With the mastery of any new technology begins a new pedagogical thinking of the teacher: clarity, structure, clarity of methodological language, the emergence of a reasonable norm in methodology.

The use of pedagogical technologies focused on productive learning activities implies an increase in cognitive activity, interest in knowledge, the 
development of initiative, creative activity, the creation of an interactive educational environment, a combination of independence and responsibility of the student as a subject of educational and cognitive activity for the process and result of the study.

Thus, the relevance of the study is determined by the social need for specialists with a high quality of professional language competence and the need to subject a detailed study of the process of its development in the system of multilevel education in a modern university. The analysis of pedagogical practice and the results of special studies suggest that the problem of using these technologies for the development of future specialists in non-linguistic universities speech competence is in the process of teaching the Russian language has not yet been sufficiently reflected in the research of scientists. Despite the available research in the aspect of increasing the effectiveness of teaching with the use of pedagogical technologies in higher education, many problems, in particular, the use of pedagogical technologies in teaching the Russian language are poorly resolved both in theoretical and practical aspects. The incompleteness of the theory of an integral and continuous system of multi-level language training of future specialists, the numerous needs of modern university practice, the need to generalize best practices, systematize the language training of future specialists in non-linguistic universities, the lack of a specific methodology for the introduction of pedagogical technologies and their improvement in the process of teaching Russian language and determined the choice of the research topic «Pedagogical technologies for the development of the speech competence of future specialists in non-linguistic universities». Compliance of the topic with the priority areas of scientific research in the Republic.

Political, economic and social problems occurring in the Republic of Uzbekistan lead to radically new approaches to various spheres of society, including the field of education. Our state, which has embarked on the path of democratic development, needs highly educated, comprehensively developed citizens, who are, first of all, an individual. Personality upbringing is a didactic priority task assigned to the educational system of the Republic by the Law on Education and the National Program for Personnel Training. That is why the use of modern technologies in pedagogical activity is one of the priority areas of education in our country. This is due to the need to train highly qualified specialists capable of actively participating in the economic, social and political spheres of our state, solving national economic, legal, educational and other tasks that are essential for our state.

The Republic of Uzbekistan is currently entering the stage that can become an important stage in the realization of its economic potential. In the country, the demand for skilled labor is growing at a faster pace than the supply, and the discrepancy between the professional knowledge and skills of university graduates and the needs of the market is obvious. In addition, while the development of innovations and technologies is an important factor of economic growth in any modern economy, in the Republic of Uzbekistan it is important to improve the correspondence of the knowledge and skills of university graduates to the needs of the market, as well as to create and strengthen an innovative infrastructure that contributes to improving the quality and market significance of activities. universities in general and stimulating the use of creative and innovative approaches to learning. The Republic of Uzbekistan has chosen and is implementing a course towards building a democratic rule of law and civil society. The main goal and driving force of the reforms carried out in the republic is a person, his all-round development and well-being. The most important condition for the development of the country is the functioning of a perfect training system based on the development of the modern economy, science, culture, technology, technology. The implementation of the National Program for Personnel Training provides for a radical reform of the structure and content of continuing education. A radical change in the existing systems of education and personnel training in the course of the implementation of the National Program is carried out based on social experience and the achievements of modern scientific thought, advancing scientific and methodological support of the educational process at all stages, in all forms and types of educational institutions of the continuous education system. Among the urgent tasks of pedagogical science at the present stage is the scientific provision of goals, content, methods, means and organizational forms of education, training and personal development based on the use of the achievements of science, technology, and advanced technologies. The state policy in the field of personnel training provides for the formation of a diversified personality of a citizen through the system of continuous education. In this regard, the individual acts in the system of continuous education and training, both as a consumer and as a producer of educational services. In particular, a person as a producer of educational services takes part in the transfer of knowledge and experience in the process of education, activities in the field of material production, science, culture and services. Individuals in the republic have the right to choose a professional educational program to realize their creative potential. Higher education occupies a special place in the system of continuous education. Higher education based on general secondary, specialized secondary, vocational education is an independent type of continuous education system and is carried out in accordance with the laws of the Republic of Uzbekistan "On Education" and "On the National Program for Personnel Training". In accordance with the National Program for Personnel Training, the main goals and objectives of higher education have been identified, one of which is to provide highly productive education and training of qualified personnel on the basis of modern educational and professional programs.

Therefore, the main goal of the National Program is as follows: a radical reform of the education sector, a complete rejection of its ideologized blinkering, and the creation of a National system for training highly 
qualified personnel at the level of developed democratic states that meets the requirements of high spirituality and morality. The content of the research includes issues of the development of society and education, the regulatory framework of public education and legislative norms, advanced educational technologies and pedagogical skills, the use of information and communication technologies in the educational process, modern approaches and innovations in teaching practical Russian language, modern methods of organization educational process and is aimed at the formation of knowledge, abilities, skills, qualifications and competencies. At the present time, there is a need for a new teaching model, built on the basis of modern pedagogical technologies, which implements the principles of student-centered education. Pedagogical technologies, considered as one of the components of a holistic learning system, not only facilitate access to information, open up opportunities for variability of educational activity, its individualization and differentiation, but also allow to organize the interaction of all subjects of learning in a new way, to build an educational system in which the student was would be an active and equal participant in educational activities.

The introduction of new pedagogical technologies in the educational process makes it possible to activate the learning process, implement the ideas of developing education, increase the pace of the lesson, and increase the volume of students' independent work. Education based on pedagogical technologies meets the following principles:

the principle of modularity ensures differentiation and individualization in teaching, independence of students, grading, variability, structuring, blocking of educational material; the principle of systematic dosing of educational material, consistency of work with it, economy of study time, generalization of training; the principle of problematicity includes a conglomeration of the following components: reflection, correction of actions when applying rules in new writing conditions, motivation, conscientiousness, strength, consistency of conclusions when faced with conflicting and inconsistent facts from the field of spelling; the principle of cognitive visualization contains the requirements of the principles of accessibility, visibility, cognitive activity, aesthetic and emotional orientation of training. The introduction of pedagogical technologies into teaching practice is carried out through the use of software and pedagogical tools. Existing modern teaching aids should be included in the educational process not by chance, not in isolation from each other, but in a certain system. The tasks of modernizing education cannot be solved without the optimal introduction of pedagogical technologies in all its areas. The use of pedagogical technologies gives impetus to the development of new forms and contents of traditional types of activity, which leads to their implementation at a higher level.

The modern teacher is faced with the problem of finding a new pedagogical tool. In this regard, there is an increasing need for language teachers who are proficient in pedagogical technologies, who are able to design, model new ideas and directions in the teaching practice of higher education.

Considering pedagogical technologies for the development of the speech competence of future specialists in non-linguistic universities, we note that the issue of the possibilities of technologizing the educational process for many years has been the subject of scientific disputes due to the probabilistic nature of its course. However, scientists agreed that the educational process can be recognized as taking place at the technological level if reproducibility and measurability of its results are guaranteed.

In contrast to standardized content, teaching techniques can vary. Depending on the set learning goals and their various combinations, a certain set of learning models is formed. Pedagogical technology is a project and implementation of a system of sequential deployment of pedagogical activities aimed at achieving the goals of education and personal development of students, guaranteeing the reproduction of learning outcomes regardless of the teacher's personality. The quality of training students of nonlinguistic universities for professional activities largely depends on personality-oriented, developmental, teaching and educational technologies. This takes into account the psychological and pedagogical characteristics of students, their motivation to obtain a profession.

The theories of pedagogical systems and pedagogical technologies are devoted to the works of V.P. Bespalko, V.V. Guzeeva, V.I. Zagvyazinsky, M.V. Klarina, V.V. Kraevsky, H.H. Mikhailova, G.K. Selevko, S.A. Smirnov and others. The technologies of students' project activities are reflected in the works of E.S. Polat, M.B. Pavlova, M.B. Romanovskaya, I.D. Chechel; in the concept of problem learning by Yu.K. Makhmutova, in the classification of teaching methods Babansky, M.I. and others.

The works of Professor M.Kh. are devoted to the issues of pedagogical technologies and pedagogical skills in national education. Tokhtakhodjaeva, Doctor of Pedagogical Sciences, Professor V.I. Andriyanova, M.G. Voinova, as well as Russian scientists such as B.L. Zankova, V.V. Davydova, P. Ya. Galperin, D.B. Elkonin and others. The work of V.G. Aseeva, L.I. Bozovic, A.K. Markova, A.A. Reana, P.M. Jacobson and others.

The works of foreign and domestic authors Yu.E. are devoted to the issues of self-actualization, personal orientations. Alyoshina, L. Ya. Gozman, M.V. Zagika, M.V. Crozat, A. Maslow, R. May, K. Rogers, F. Pearl, E. Shostrom and others.

Ideas, methods and approaches in the field of continuous, multilevel professional education were developed in the scientific works of A.T. Glazunov, E.F. Zeer, I.P. Smirnova, E.V. Tkachenko, F.T. Khamatnurov and others.

\section{Discussion}

The main purpose of the study is to develop and improve effective methods of using pedagogical 
technologies for the development of speech competence of future specialists from non-core universities. Modern pedagogical technologies serve as a tool for the implementation in practice of new learning systems that have higher educational characteristics in comparison with traditional didactic systems. On the one hand, they focus on achieving the required level of efficiency and quality of education, on the other, while maintaining frontal forms of education as the main ones, they provide each student with the opportunity to study according to individual programs, taking into account in full his cognitive abilities, motives, inclinations and other personal quality. The accompanying task of the research is to characterize the applied pedagogical technologies of teaching speech skills within the framework of the course «Culture of speech» at the faculties of "Mining" and "Energy mechanics" of the Navoi State Mining Institute. The methodological basis of the study was the state documents on the education of the Republic of Uzbekistan, the works of domestic and foreign authors on this issue.

Research methods. The following methods can be used at various stages of the study:

- theoretical - understanding the problem and the subject of research, modeling the pedagogical process, theoretical generalization of research results, taking into account specific conditions and new facts;

- empirical - comparative-comparative analysis of the results of ascertaining and formative experiments, observation, conversations, questionnaires, pedagogical experiment;

mathematical - registration, mathematical and statistical processing of the results.

The scientific novelty of this paper is that:

- the work provides a substantiation of the role and place of pedagogical technologies in the classroom on the subject «Culture of speech» for students of nonlinguistic universities;

- the principles of using pedagogical technologies as effective methods contributing to the development of speech skills of students of non-linguistic universities are identified and substantiated;

- the set of pedagogical technologies has been identified and substantiated, in which the foundations of the speech communicative competence of students are formed;

The theoretical significance of the study is that it:

- the organizational and substantive parameters of the implementation of the tasks of pedagogical technologies - training at a university were theoretically comprehended;

- the possibility of using pedagogical technologies in teaching language skills is substantiated at the scientific level.

The practical value of the study lies in the fact that a scientifically grounded and experimentally proven method of teaching speech skills using pedagogical technologies helps to increase the general and subject level of learning, can be used in the development of methodological techniques for mastering speech skills; research materials can serve as the basis for the creation of an educational and methodological complex and a textbook on the development of speech skills for specialties in non-core universities.

As in other countries, higher education in Uzbekistan involves the training of qualified specialists for various spheres of public life and sectors of the economy - scientific, economic, technical and others. The educational process involves the systematization of knowledge and acquired skills, orienting students towards solving theoretical and practical problems in the vector of the chosen specialization with the creative use of the achievements of modern thought and technology.

The state educational standard of higher education defines:

general requirements for the quality of training, the content of education;

necessary and sufficient level of preparedness of students and general qualification requirements for graduates of educational institutions.

The main feature of the program is the continuity of education. Each person has the opportunity to acquire knowledge, professional skills and specialties throughout his life. This program creates an effective mechanism of the educational system, in which the main components are present:

- the formation of a free-thinking person, his moral, spiritual and physical development;

- respect for the individual, disclosure of creativity and abilities;

- progressive training, obtaining professional skills and full self-realization of the individual in life.

In this regard, I would like to draw your attention to such a concept as rhetorical competence. It is no secret that the effectiveness of the assimilation of material by students is influenced by the availability, clarity, and accuracy of teachers' use of turns of speech, rhetorical techniques, which may include not only speech figures, but also elements of artistry. But do all teachers possess this knowledge and skills: the skills of public speaking, building effective speech. Unfortunately, we cannot give a positive answer to this question with complete confidence. Students often face cases of poor teaching of courses. And this is not about teaching methods, but about the speech skills of teachers. And this happens not because the teacher does not know his subject, he does not possess the skills of building coherent, logical, effective speech, which is the main obstacle for a fruitful dialogue "teacher-student". The solution to this problem could be the inclusion of such a subject as rhetoric in the obligatory part of the curricula of universities in all areas without exception.

Today rhetoric is no longer even an academic discipline, but a professional one. In the modern world, people who have the skills of oral speech, both public and dialogical, prosper. And to a greater extent, a teacher must have such skills - the ability to logically correctly, reasonably and clearly build oral speech. These skills are developed during the study of the course "Rhetoric".

Today on the Internet you can find many links to various schools of public speaking. People are interested, trainings take place. Therefore, there is demand. People want to communicate competently, 
build dialogues, speak in public, convey their thoughts to the audience, convince and convince. And this fact confirms the necessity of introducing the Rhetoric course into the curricula of universities, particularly in pedagogical universities.

Rhetoric is one of the most ancient philological sciences, in European culture it originates from the ancient Greek rhetorical schools, where it was formed as an academic subject, later as a science. Initially, the subject of rhetoric was live speech, verbal skill, eloquence. The first works on rhetoric were written in the 5th-3rd centuries BC (Gorgias, Lysias, Plato, Aristotle).

Oral speeches did not reach us, but the doctrine of these speeches was expounded in one of his dialogues by Plato - a disciple of Socrates and the greatest thinker of the ancient world. In rhetorical teaching, the most important attention was paid to the content of speech, its construction, verbal expression, memorization and mastery of public speaking, speech was closely related to poetics, the doctrine of styles, logic, philosophy.

In Rome, poetry, science, and rhetorical skill were highly valued. The rhetorical schools in Rome flourished, Mark Tullius Cicero, Julius Caesar, Mark Junius Brutus are still recognized as unsurpassed orators.

The social status of the speaker rises, recognition of his role in social life reaches extraordinary heights. It was at this time that entire treatises on the speaker were written. The supreme example of this is M.T. Cicero (106-43 BC) combined the skill of an orator, a poet, a statesman, and the scholarship of a rhetorician. His works - "On the orator", "Orator", "Brutus". He is both a philosopher and the author of the treatises On Fate and On the Nature of the Gods. Cicero asserts: the properties of an orator are activity, courage, sociability, versatility of interests, an orator is a thinker, and in anxious situations - a warrior.

The role of rules, training in the field of eloquence is increasing. Knowledge of rhetorical techniques and lengthy exercises become necessary. This line in Roman rhetoric was especially elaborated by Marcus Fabius Quintilian ( AD 36-96). The famous "Twelve Books of Rhetorical Admonitions" by Quintilian have no analogue in the history of rhetoric, they are still used by all orators.

The famous German historian, author of the multivolume "History of Rome" Theodor Momsen wrote about this work of Quintilian as follows: "The textbook of rhetoric compiled by him ... is one of the best works that have come down to us from Roman antiquity; he is distinguished by delicate taste and fidelity, simplicity of feeling and image; lively and relaxed, instructive and exciting; in general, all this work is, according to the author's own idea, the complete opposite of the abundant phrases, but poor in thought, the literature of that time "[3]. The essence of rhetoric, according to Quintilian, is the union of thought and word. The aesthetic factor plays an important role in the skill of eloquence. Cicero put speech at the head of all things, the laws of nature, the duties of people, for knowledge of all these things enters the life of people through speech. Cicero writes:
"Before whom do people tremble? Who are they looking at, shocked when he speaks? Who is admired? Who is considered almost a god among people? The one who speaks harmoniously, shining with bright words and vivid images, introducing even into prose itself a certain poetic dimension, in a word, beautiful" [6].

Speaking about higher education today, we mean the formation of personal competencies, which are formed in the process of mastering the humanitarian, social, psychological and pedagogical disciplines and include: communication, the ability to conduct training, counseling, research, forecasting, application of knowledge in practice, etc., therefore, communicative competence is an integral part of the competence approach in determining the content of education.

At the present stage of education, special attention is paid to the formation of communicative competence. The structure of communicative competence includes the following elements: linguistic, linguistic, speech, cultural and rhetorical competence.

In this article, we will consider the issues of forming the rhetorical competence of specialists from non-core universities.

The very concept of "competence" is associated with the modernization of the higher education system in line with the competence approach.

However, most researchers consider only one or several aspects of pedagogical activity, and, therefore, pay attention to the formation of one or another quality that is part of professional competence.

Initially, the term competence was used in pedagogy only in relation to the study of a foreign language and the ability to express one's thoughts by means of this language.

The term "competence" was first used by $\mathrm{N}$. Chomsky, a professor at the University of Massachusetts (United States of America) in 1965. By competence, he understood "the speaker's knowledge of the language", distinguishing it from the "use of language." However, there is still no unambiguous understanding of the term "competence": “... on the one hand, this is the goal of learning, on the other, its content, on the third, the result, and on the fourth, a means of achieving the learning outcome".

The competence of a specialist in a particular area forms the specialist's readiness to perform a professional role and makes it possible to solve production problems. And since the solution of professional tasks in many areas is impossible without building a system of communication links and effective communication, we can confidently assert that without the formation of rhetorical competence, full-fledged training of a specialist is impossible.

And then, rhetorical competence can be defined as a body of knowledge about communication, which is realized in the sphere of increased speech activity of a specific professional or social group; rhetorical skills that can be applied in standard and non-standard speech situations.

Rhetorical competence is the highest level of communicative competence that ensures a person's rhetorical activity [7]. 
Rhetorical competence - the ability to create, pronounce the original text of a certain speech genre, to show empathy in accordance with the addressee's need, the purpose of the speech and the situation of public speech.

For the formation, development and improvement of rhetorical competence, it is necessary to master such rhetorical skills as:

- invention of thought;

- the formation of goals, objectives, the choice of a genre and the corresponding type of speech for effective speech communication;

- definition of the type of addressee, especially communication with him;

- the disposition of thought, the logic of presentation, the choice of the most acceptable way of expressing consent, expressing refusal, refutation;

- determining the appropriateness of the use of a particular language unit in a given speech situation;

- skillful use of rhetorical techniques for effective communication with the aim of influencing, convincing the addressee.

- skillful use of intonational highlighting of keywords, etc.

The formation of speech culture as an integral part of professional culture includes communicative competence, which allows you to work successfully in the chosen field of activity.

The effective formation of the rhetorical component of the communicative competence of students in noncore areas of training is possible with the implementation of the system-activity approach in teaching.

Successful verbal behavior is not only correctness, accuracy, consistency, it is also non-verbal influence as a means of transmitting information; general requirements for the appearance of the speaker, his clothes, hairstyle, demeanor in front of an audience; this is the use of facial expressions and gestures, etc.

The concepts of rhetoric and culture of speech are close in meaning in relation to rhetorical competence.Today, the curricula of non-core universities of the Republic does not include the discipline "Rhetoric", the content and goals which are aimed at mastering not only philological knowledge, but also mastering speech skills, forming rhetorical competence. It is necessary to develop programs for the gradual formation of the rhetorical competence of future specialists from non-core universities, a set of means and methods, techniques for the formation of culture, etc.

The success of a modern person in any activity directly depends on his communicative competencies.

By developing the skills of independent expression, we teach our young people to think critically, create, remember, speak, because it is these forms of activity that ensure the successful implementation of all other skills and abilities of an educated person.

Modern society and the state impose increased requirements on the level of training of university graduates who possess the necessary professional competencies at a high level, including communicative competence. New tasks for the formation of personality have been set for education today. "Speech education" of a university graduate affects his competitiveness in the labor market, successful socialization in the future. However, in recent years, teachers, psychologists, linguists, specialists in other fields of knowledge have noted that the level of students' proficiency in speech competence is not high enough and does not fully meet the requirements for a specialist in any field today, although this competence is the most important component of professional training.

This means that a university graduate must be able to choose a strategy and tactics of communication, establish verbal contact and adjust his behavior in accordance with the situation and communicative intention; be able to reasonably state your point of view and conduct a discussion in accordance with the principles and rules of a constructive dispute; master the tactics of countering manipulative speech influences.

It should be noted that at present, the problem of developing the speech competence of students of nonlinguistic universities in the classroom in language disciplines has not been sufficiently developed, because these disciplines are aimed at studying the structure of the language, comparative analysis, translation, etc., but not teaching speech skills. Here it is appropriate to refer to the classifier of directions and specialties of higher education of the Republic of Uzbekistan. The area of the specialty "Humanities" is represented by the following areas:

- Philology and language teaching (by language);

- Literary criticism (by languages and areas of research);

- Linguistics (by language);

- Classical philology (by type);

- Textology and literary source studies;

- Theory and practice of translation (by language);

- Comparative linguistics, linguistic translation studies (by language).

It also establishes the following requirements for the content of educational disciplines in the humanitarian block:

- develop and supplement the knowledge gained on the basis of general secondary and secondary specialized, vocational education; to form a scientific and humanitarian worldview, high spirituality and democratic culture, economic, legal and creative thinking, conviction and social and political activity based on the idea of national independence and democracy, national and universal values;

- ensure the focus of education on its organic unity with history, philosophy, folk traditions and customs; preserve and enrich the culture of the peoples of Uzbekistan, respect for the history and culture of other peoples;

- develop humanism, patriotism and internationalism;

- to ensure the orientation of training and education on the formation of an independently thinking, capable of making decisions, comprehensively developed, harmonious personality. 


\section{Results}

Proceeding from these requirements, it would be advisable to add the direction of "speech education" to the existing directions of the humanitarian block. it is clear that in order to teach the speech skills of specialists in non-linguistic universities, specialists with speech education are needed who are able to teach the skills of speech interaction, methods of argumentation and refutation, as well as knowledge of the basics of speech culture, on which the skills of conducting a cultural dialogue, orientation in an everincreasing flow of information are based; able to teach the construction of public speaking and debate, etc. And to solve this problem, we must solve a number of tasks:

- to identify the components of speech competence, the assimilation of which involves the development of students' ability to build a speech work in accordance with a specific situation;

- to create a structural model for the development of students' speech competence, including a competencebased and personality-oriented approach, forms of education, teaching aids and assessment tools;

- to develop a set of tasks / study guide for the development of speech competencies of specialists in non-linguistic universities.

In our country, improving the system of continuous education, improving the quality of educational services is a priority task outlined in the Decree of the President of the Republic of Uzbekistan "On the Strategy of Actions for Further Development". Consequently, ample opportunities have been created for conducting practical research to improve the level of methodological training of future specialists, ensuring the integration of the personnel training system with the priority areas of development of science and technology.

The "Strategy of actions for the further development of the Republic of Uzbekistan" identified priority tasks for improving work in the field of state youth policy, bringing up a harmonious, intellectually developed young generation, bringing the quality of education in higher educational institutions to the level of compliance with the current and future needs of the individual, society and the state.

The solution to this problem could be the introduction of a practical course of rhetoric into the curricula of non-core universities, and as part of the course, the creation of textbooks and teaching aids in accordance with the qualification requirements for a university graduate in the Republic of Uzbekistan.

And here we must understand that rhetoric is not a linguistic course in the Russian language. Rhetoric is distinguished by its goals, objectives, content and structure. In this regard, we are faced with an urgent and socially significant task of creating modern pedagogical technologies for the development of speech skills of specialists. And these technologies should contribute to the development of the personal orientation of the educational process. And here the question already arises about not "what to teach?" But "how to teach?" (A.B. Khutorskoy).
Speech skills are formed only as a result of purposeful work based on special methods and techniques. This work can be realized only within the framework of a special academic subject with its own content, logic of presentation and technology.

Today, as never before, the issue of "speech education" has become relevant. We must understand that along with professional skills (hard skills); we must improve speech skills (soft skills).

As you know, the activities of educational institutions are aimed at mastering hard skills, and there are certain levels of difficulty in mastering professional skills. So why are there no mastery levels for mastering soft skills?

There are certificates and diplomas to confirm hard skills. Soft skills are not certified and can only be proven in practice. Soft skills are learned more slowly than hard skills. To master Soft skills, systematic practical exercises are required.

For this, it is necessary to improve the methods of teaching speech disciplines. As you know, there are two areas of research in linguistics: in one area, language systems are studied, in the other, speech. Unlike linguistics, rhetoric deals only with speech, not language.

In our work, we set the task of improving speech skills, i.e. the object of study is speech activity, speech communication and behavior. Modern rhetoric is not the study of the structure of the language, and not even the study of the culture of speech as such, rhetoric combines knowledge about a person from the theory of communication, psychology of communication, linguistics, ethics, sociology, logic, philosophy, etc.

Today there is a lot of literature on rhetoric, scientific works. We, given the mentality of our society, must adapt it to the new needs of our time.

A specialist meeting modern requirements should know:

- features of speech use in writing;

- basic principles and rules of effective speech communication, stages of creating a speech work;

- basic principles and rules of effective speech communication;

Be able to:

- choose a strategy and tactics of communication, establish verbal contact and adjust their behavior in accordance with the situation and communicative intention;

- build a monologue speech, guided by the rules of the rhetorical canon;

- to reasonably state their point of view and conduct a discussion in accordance with the principles and rules of a constructive dispute;

- analyze speech actions from the point of view of their success / failure and draw practical conclusions from this analysis.

Own:

- skills of effective use of expressive means of the Russian language in different communication situations;

- tactics of countering manipulative speech influence; 
- terminological apparatus of modern rhetoric (neorhetoric)

- must demonstrate the ability and willingness to apply the acquired knowledge in practice.

- to achieve the set goals, it is necessary to solve certain problems, which includes:

- improving the technology of developing the speech competence of future specialists;

- creation of a model for the development of speech competence of students of non-linguistic universities, as well as the development of a substantiated and special set of practical tasks / tutorial for the development of speech competence.

- development of a structure for improving technologies for the development of speech competence of future specialists.

\section{Conclusion}

Today there are a number of technologies that contribute to the development of skills and abilities. These are the so-called interactive teaching methods. Relevant in modern teaching methods is the use of interactive teaching methods. But this does not mean that teachers of language disciplines should give up everything that has been accumulated over many years. The specificity of language learning is such that it is a means of studying all other disciplines.

The goals of language learning, as you know, are personal, meta-subject and subject, which in turn have such sub-goals as the ability and readiness for selfdevelopment, interdisciplinary knowledge, cognitive, communicative, etc.

The most effective in teaching the speech aspect of the language is the competence-based approach. When developing competencies, we must pay special attention to the formation and mastery of various types of speech activity; the basics of the culture of oral and written speech; implementation of the speech-thinking process; creation and reproduction of speech in accordance with the target communicative setting. Also important is the cultural approach, i.e. mastering the language by mastering the norms of speech etiquette, the culture of interethnic communication, reflecting the historical experience of the people.

The teacher's innovative activity is designed to search for new interactive teaching methods. The main techniques of the interactive methodology are language learning in the community, learning in collaboration.

Various teaching methods can be used here. Yu.K. Babansky offers methods of organizing educational activities; methods of stimulating and motivating cognitive activity; method of control and self-control. A.V. Dudnikov offers inductive and deductive methods and their combination.

L.P. Fedorenko offers such a method as sources of knowledge, which uses such techniques as questions (direct analytical, synthetic, rhetorical, suggestive, etc.); reception of drawing up a plan on the go; recording the main provisions of the message; compilation of reference notes, tables, diagrams, etc.
A number of methodologists offer analysis of texts, presentation, composition as a type of work on the development of speech.

M.I. Makhmutov provides a rationale for problem learning as a didactic system and type of learning. The problem learning method is presented in the form of a structure: problem task + problem situation.

It is a flexible combination of different methods of teaching a language based on a culturological aspect, applied in the classroom together with a variety of teaching technologies, that will help motivate students and become effective in mastering languages in the future. At the same time, common to all interactive methods is the use of individual and group activities, and, of course, the collective work of students is a compulsory activity.

The use of interactive methods develops a culture of participation in dialogue, a culture of constructive debate, competent argumentation, helps to establish emotional contacts between students, develop creativity, the ability to think outside the box and be able to defend their interests, form teamwork skills, providing high motivation in self-development and self-study, active life position, disclosure of creative potential, which is an integral prerequisite for the formation of speech skills.

To date, an analysis of rhetorical knowledge shows how relevant this problem is and is not yet sufficiently understood and studied in the educational process.

\section{References}

1. A.S. Belkin, V.V. Nesterov Pedagogical competence. Ekaterinburg, (2003)

2. N.L. Goncharova, Categories "competence" and "competence" in the modern educational paradigm. Collection of scientific papers of the North Caucasus State Technical University. Series "Humanities.", 5, (2007)

3. A.V. Khutorskoy, Technology for designing key and subject competencies, Eidos Online Journal, (2005)

4. L.N. Gorobets, "Pedagogical rhetoric": theory and practice of teaching non-philological students of rhetorical competence: monograph. - Armavir: Publishing and Publishing Center of ASPU (2007)

5. L.P. Aksenova, Fundamentals of the rhetorical culture of the teacher. Ekaterinburg (2002)

6. Appendix No. 2 to the Resolution of the Cabinet of Ministers of the Republic of Uzbekistan dated August 16, 2001 No. 343 "On the Approval of State Educational Standards of Higher Education".

7. V.I. Annushkin, Rhetoric. Introductory course: textbook. M.: Flint; Science, 224 (2018)

8. Y. V.Vorsina, T. A. Snigireva, To the Issue of the Competence For- mation Criteria, The Education and Science Journal DOI: https://doi.org/10.17853/1994-5639-2012-10-6778 
9. O. Ukpokodu, Developing Teachers' Cultural Competence: One Teacher Educator's Practice of Unpacking Student Culturelessness, Action in Teacher Education, 432-454, 33 (2012) DOI: https://doi.org/10.1080/01626620.2011.627033

10. K. Cushner, Teacher Education, The SAGE Encyclopedia of Intercultural Competence, (2017) DOI: http://dx.doi.org/10.4135/9781483346267.n264

11. Fritz K. Oser, F. Achtenhagen and U. Renold, Competence Oriented Teacher Training: Old Research Demands and New Pathways, Competence Oriented Teacher Training, Brill Sense (2006) DOI: https://doi.org/10.1163/9789087903374_002

12. B. Cherednichenko, N. Hooley, T. Kruger, R. Mulraney, The practice of beginning teachers: Identifying competence through case writing in teacher education, Australian Journal of Teacher Education, 22 (1997) DOI: http://doi.org/10.14221/ajte.1997v22n2.3

13. R. Gillies, Teachers' and Students' Verbal Behaviours During Cooperative Learning, The Teacher's Role in Implementing Cooperative Learning in the Classroom, 238-257 (2007) DOI: $10.1007 / 978-0-387-70892-812$

14. John H. Sloan, Understanding McLuhan: Some implications for the speech teacher and critic, The Speech Teacher, 17, 2 (2009) DOI: https://doi.org/10.1080/03634526809377665

15. Elizabeth Norwood A rationale for effective teacher education in speech communication, (2009) DOI:https://doi.org/10.1080/03634527509378151

16. M. Hochmuth, Great teachers of speech, The Speech Teacher, 4(3) (2009) DOI:https://doi.org/10.1080/03634525509376741

17. III. Wayland Maxfield Parrish, Great teachers of speech, The Speech Teacher, 4(3) (2009) DOI:https://doi.org/10.1080/03634525509376741

18. R. K. Tucker, The speech teacher in American industry (2009) DOI:https://doi.org/10.1080/03634526009377092

19. M. Kinnane, Promoting speech education, (2009) DOI: https://doi.org/10.1080/03634526609377547

20. M. Ogilvie, Student teaching in speech (2009) DOI:https: //doi.org/10.1080/03634525309376586

21. A.A.Volkov, The course of Russian rhetoric: $a$ manual for theological educational institutions, Russian linguistic journal, 2(6), 35 (2016)

22. A.A. Volkov, Theory of rhetorical argumentation, KDU Publishing House (2013)

23. I.M. Osmolovskaya, Innovation and teaching practice, Public Education, 6, 182-188 (2010)

24. N.N. Simonenko, Management of educational services using innovative teaching methods, Bulletin of the Pacific State University, 2, 201-206 (2012)
25. L.V. Cherepanova, Reflective approach in teaching Russian language, Science (2006)

DOI: https://doi.org/10.23683/1995-0640-2017-3202-215.

26. Appendix No. 2 to the Resolution of the Cabinet of Ministers of the RUZ dated August 16, 2001 № 343 "On the approval of state educational standards of higher education." 